\title{
Effect of pre-treatment on puffing of finger millet, bengal gram and maize and their flours
}

JAYA PRAKASH RAYA, B. ASHWIN KUMAR, D. RAVINDRA BABU AND A. SRAVANTHI

Received : 27.08.2015; Revised : 28.08.2015; Accepted : 26.09.2015

See end of the Paper for authors' affiliation

Correspondence to :

JAYA PRAKASH RAYA

Department Agricultural

Engineering, Farm

Implements and Machinery

Scheme, Agricultural Research

Institutes (A.N.G.R.A.U.),

HYDERABAD (A.P.) INDIA

Email : jayacae08@ gmail.com
-ABSTRACT : The effect of pretreatments on puffing of finger millet, bengal gram and maize were studied. The grains were pre - treated with water and citric acid solution ( $1 \%$ concentration). The puffed grains were evaluated for puffing yield, bulk density and angle of repose. All these three parameters of the puffed grains pre-treated with water. The yield (\%) of corn varied to an higher extent for about 16 per cent for puffed grains pre-treated with water than pre-treated citric acid. There was almost no effect of pre-treatments of bengal gram on the puffing of grains. The bulk density of citric acid pre-treated corn was found to be $0.659 \mathrm{~g} / \mathrm{cc}$ that is less than bulk density of water pre-treated corn puffed corn. The angle of repose of bengal gram that is pre-treated with water was $32.43^{\circ}$ and that of citric acid pre-treated was found to be $31.51^{\circ}$. The sensory evaluation of the chapatti was made with blend of the three flours of puffed finger millet, bengal gram and maize with wheat in different proportions. The chapatti made from the blend of wheat 80 per cent maize 10 per cent finger millet 5 per cent and bengal gram 5 per cent has good overall acceptability of 8.34 on ten point hedonic scale by sensory evaluation.

- KEY WORDS : Puffing, Maize, Finger millet, Bengal gram

- HOW TO CITE THIS PAPER : Raya, Jaya Prakash, Kumar, B. Ashwin, Babu, D. Ravindra and Sravanthi, A. (2015). Effect of pre-treatment on puffing of finger millet, bengal gram and maize and their flours. Internat. J. Agric. Engg., 8(2) : 248-254. 